\title{
When a coronary artery fistula is not simply a fistula: Using multimodality imaging to demonstrate an unusual embryologic remnant
}

Arash Salavitabar, MD, ${ }^{a}$ Anjali Chelliah, MD, ${ }^{a}$ David Kalfa, MD, PhD, ${ }^{\mathrm{b}}$ and Matthew A. Crystal, $\mathrm{MD}^{\mathrm{a}}$

From the a Department of Pediatrics, Division of Pediatric Cardiology and ${ }^{\mathrm{b}}$ Section of Congenital and Pediatric Cardiac Surgery, Division of Cardiac, Thoracic and Vascular Surgery, New York-Presbyterian Morgan Stanley Children's Hospital, Columbia University Medical Center, New York, NY.

Disclosures: Authors have nothing to disclose with regard to commercial support.

Received for publication Jan 5, 2018; revisions received Jan 27, 2018; accepted for publication Feb 11, 2018; available ahead of print March 13, 2018.

Address for reprints: Arash Salavitabar, MD, Division of Pediatric Cardiology, Department of Pediatrics, New York-Presbyterian Morgan Stanley Children's Hospital, Columbia University Medical Center, 3959 Broadway, CHN2-253, New York, NY 10032 (E-mail: as4136@cumc.columbia.edu).

J Thorac Cardiovasc Surg 2018;156:358-62

$0022-5223 / \$ 36.00$

Copyright (c) 2018 by The American Association for Thoracic Surgery

https://doi.org/10.1016/j.jtcvs.2018.02.032

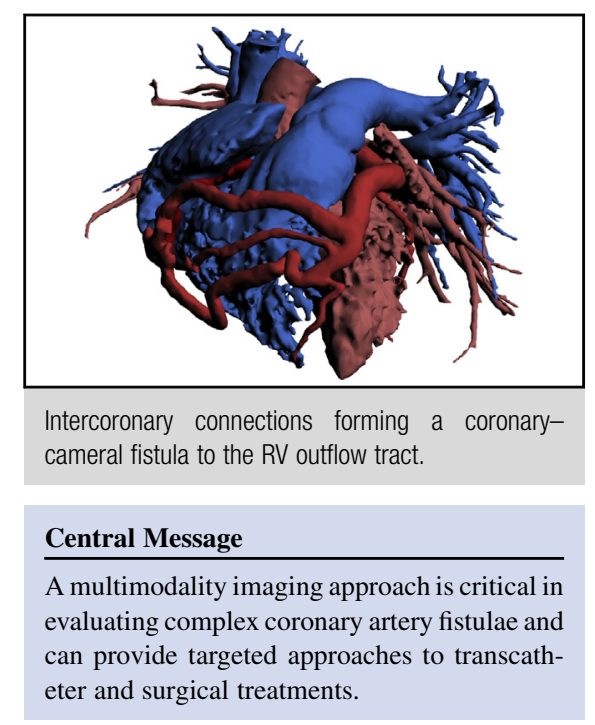

Video clip is available online.

Our approach to this unusual coronary artery fistula underscores complementary roles of multimodality imaging in delineating complex coronary artery anatomy. Murmur evaluation of this infant diagnosed right coronary artery (RCA) ostial atresia with compensatory intercoronary connections from the left anterior descending (LAD) coronary artery to the RCA and a coronary-cameral fistula to the right ventricular outflow tract. Echocardiogram demonstrated coronary-cameral fistulae to the right ventricle (Video 1), a mildly dilated left ventricle, and holodiastolic flow reversal in the descending aorta. A low-radiation electrocardiogram-gated computed tomography angiogram (effective radiation dose $0.3 \mathrm{mSv}$ ) revealed 3 connections arising from a dilated LAD to the RCA, with a normal-caliber distal LAD (Figure 1). Visualization of the RCA ostium was limited by the patient's small size and rapid heart rate. ${ }^{1}$ Three-dimensional models were digitally created and printed with hollowed-out vessel lumens for testing of catheter courses and predetermined fluoroscopic angles (Figure 2 and Video 2).

Cardiac catheterization confirmed RCA ostial atresia and demonstrated the sole source of RCA flow by the intercoronary connections, coalescing into one fistula to the right ventricular outflow tract (Figure 3 and Video 3). This comprehensive imaging approach revealed that the intercoronary connection closest to the base of the heart was likely the circle (or anastomosis) of Vieussens, ${ }^{2}$ a persistent embryologic collateralization remnant between the RCA and LCA by the conus artery. The remaining connections likely represented septal perforating branches.

Indications for fistula closure included a significant left-to-right shunt, lifelong risk for systemic steal from

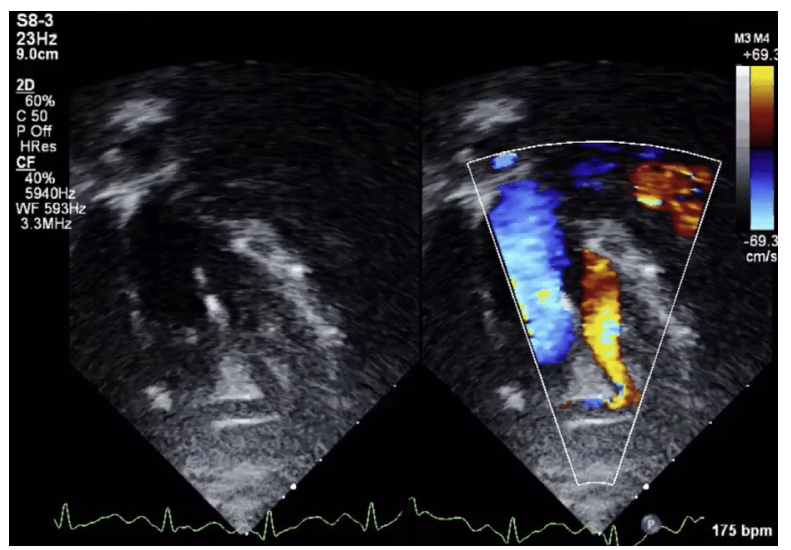

VIDEO 1. Echocardiogram showing a color-compare clip of at least 1 large vessel coursing anteriorly and rightward in an oblique apical view. Video available at: http://www.jtcvsonline.org/article/S0022-5223(18) 30395-7/fulltext. 

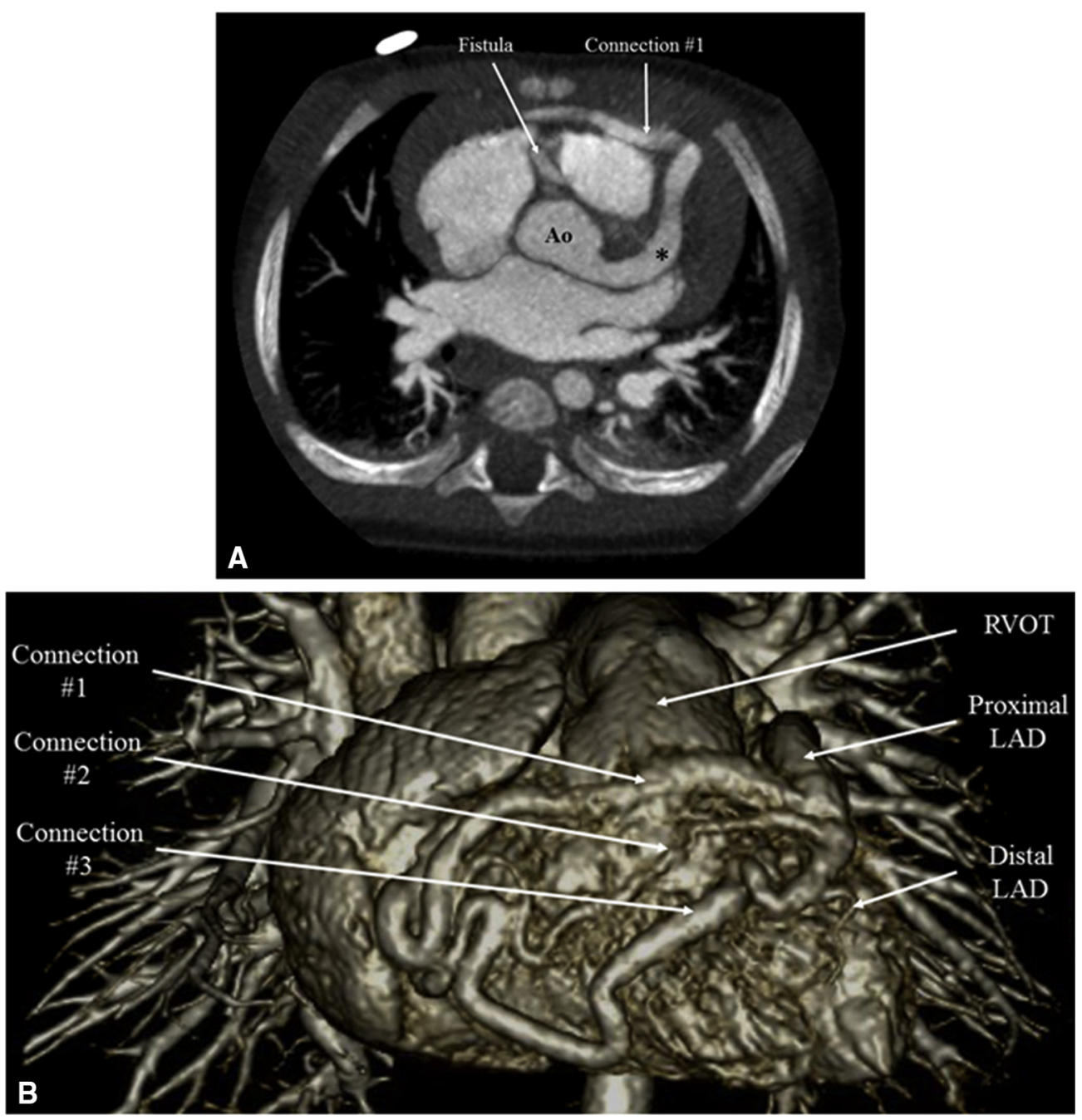

FIGURE 1. A, Coronary computed tomography angiogram showing a severely dilated left main and left anterior descending coronary artery $(*)$ with no evidence of a right coronary artery ostium, intercoronary "Connection \#1" coursing anteriorly, and the fistula coursing toward the right ventricular outflow tract in an oblique axial plane. B, Three-dimensional volume-rendered computed tomography angiogram. Ao, Aorta; RVOT, right ventricular outflow tract; $L A D$, left anterior descending coronary artery.

the distal coronary artery territory, and potential for coronary artery thrombosis. Attempted transcatheter closure of the fistula resulted in device embolization due to the dynamic nature of the surrounding myocardium. Surgically establishing a 2-coronary artery system was deferred due to the fistula's intramyocardial course. The fistula exit point was successfully closed surgically through a pulmonary arteriotomy (Figure 4 and Videos 4 and 5).
The authors thank Drs Richard Van Praagh and Robert Anderson for their assistance with interpreting the embryologic development of this patient's unique findings.

\section{References}

1. Chen SJ, Lin MT, Lee WJ, Liu KL, Wang JK, Chang CI, et al. Coronary artery anatomy in children with congenital heart disease by computed tomography. Int J Cardiol. 2007;120:363-70.

2. Rathor AL, Gooch AS, Maranhao V. Survival through conus artery collateralization in severe coronary heart disease. Chest. 1973;63:840-3. 

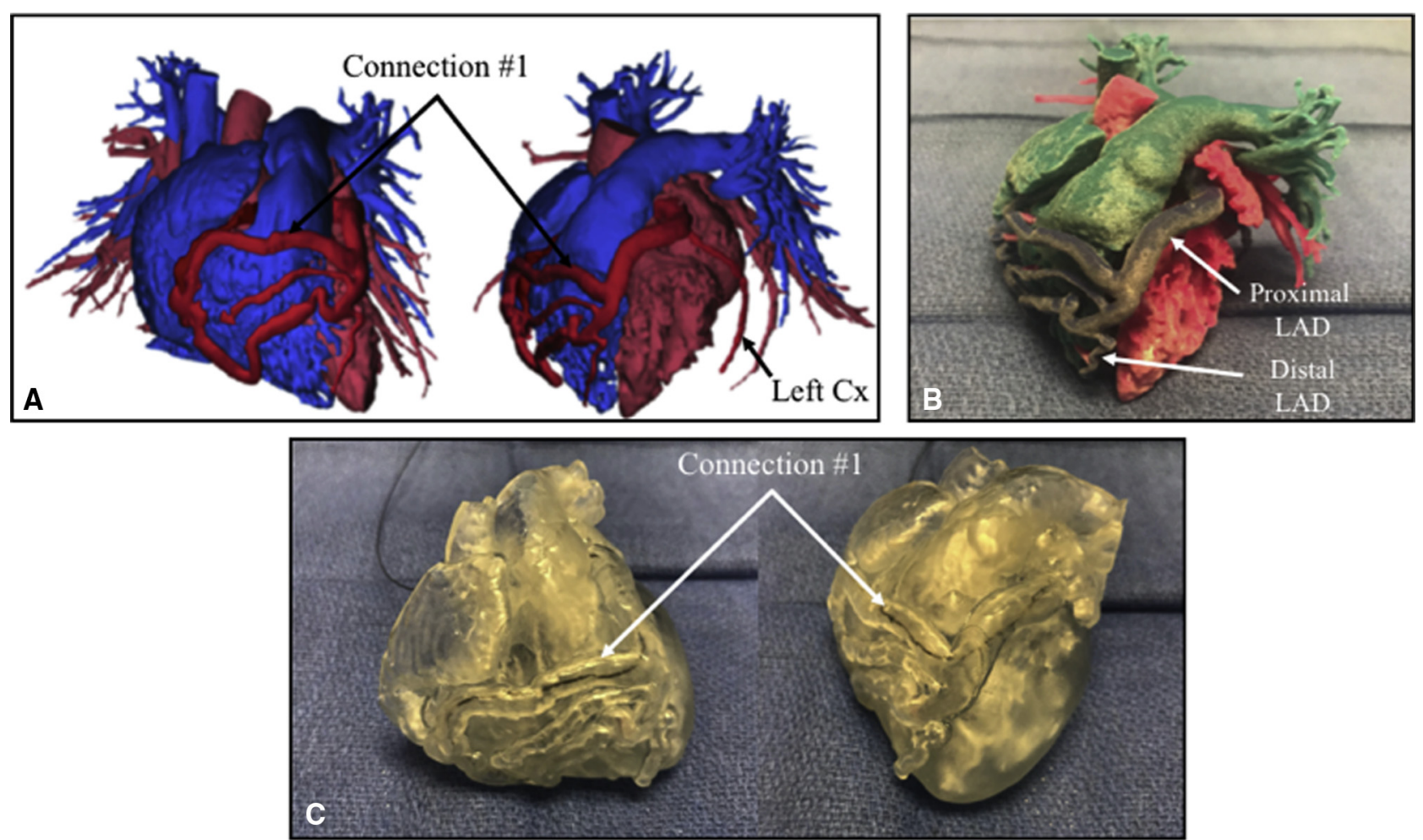

FIGURE 2. A, Three-dimensional (3D) virtual model from the anteroposterior (left) and lateral (right) views. B, 3D-printed model with left anterior descending coronary artery as labeled. C, 3D-printed model with coronary arteries and inter-coronary connections hollowed out. A wire is seen coursing from the ostium of the left main coronary artery, through the LAD, and into intercoronary "Connection \#1." Left Cx, Circumflex branch of left coronary artery; $L A D$, left anterior descending coronary artery.

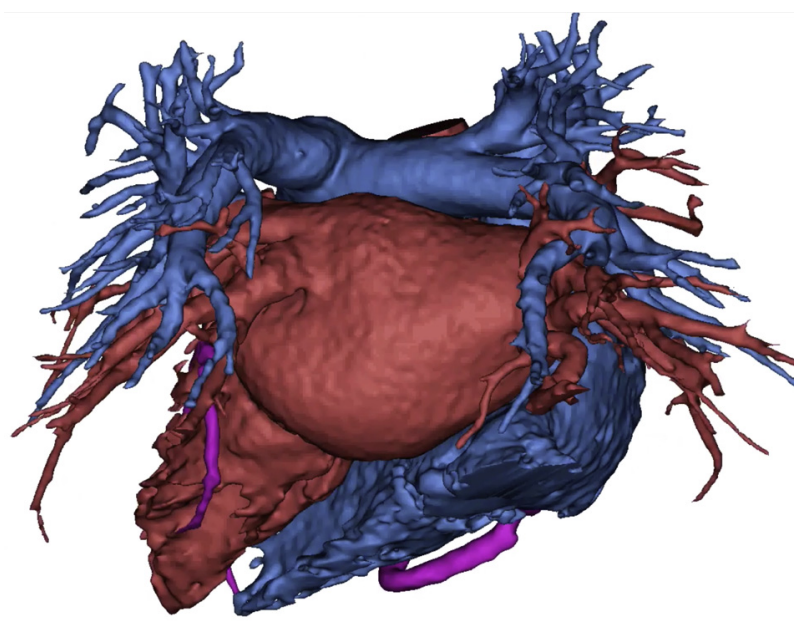

VIDEO 2. Rotating virtual 3-dimensional reconstructed model. Video available at: http://www.jtcvsonline.org/article/S0022-5223(18)30395-7/ fulltext. 


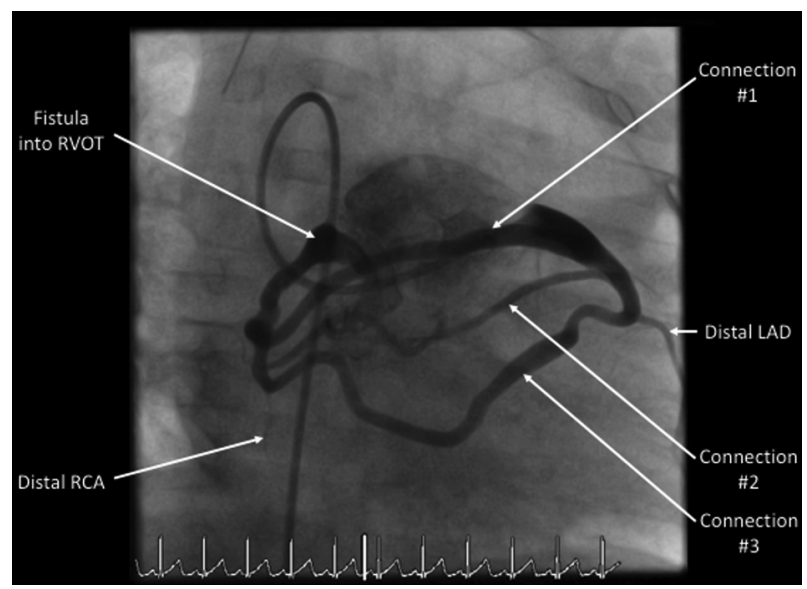

FIGURE 3. Still-frame picture of a transcatheter angiogram performed retrograde in the left anterior descending coronary artery in the anterior-posterior view. RVOT, Right ventricular outflow tract; $R C A$, right coronary artery; $L A D$, left anterior descending coronary artery.

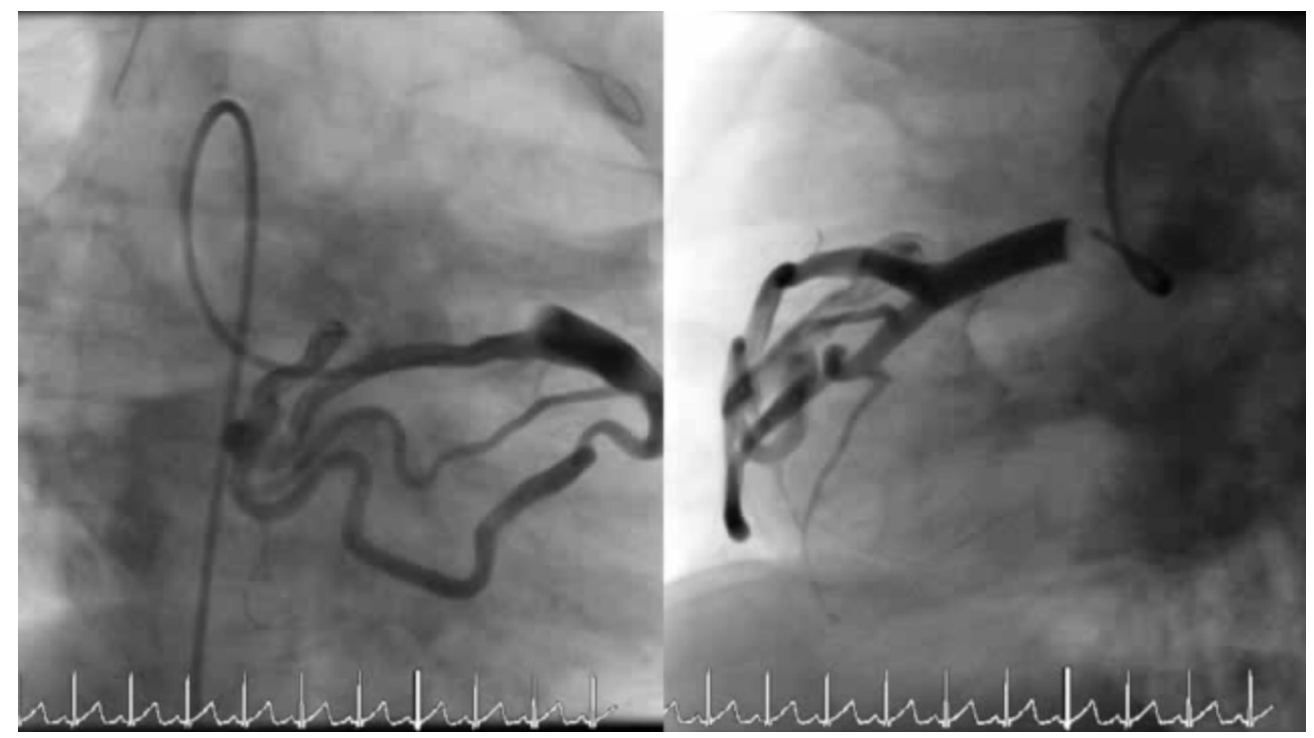

VIDEO 3. Transcatheter angiogram performed retrograde in the left anterior descending coronary artery (LAD) in anteroposterior (left) and lateral (right) views during balloon occlusion of the proximal LAD. Video available at: http://www.jtcvsonline.org/article/S0022-5223(18)30395-7/fulltext. 

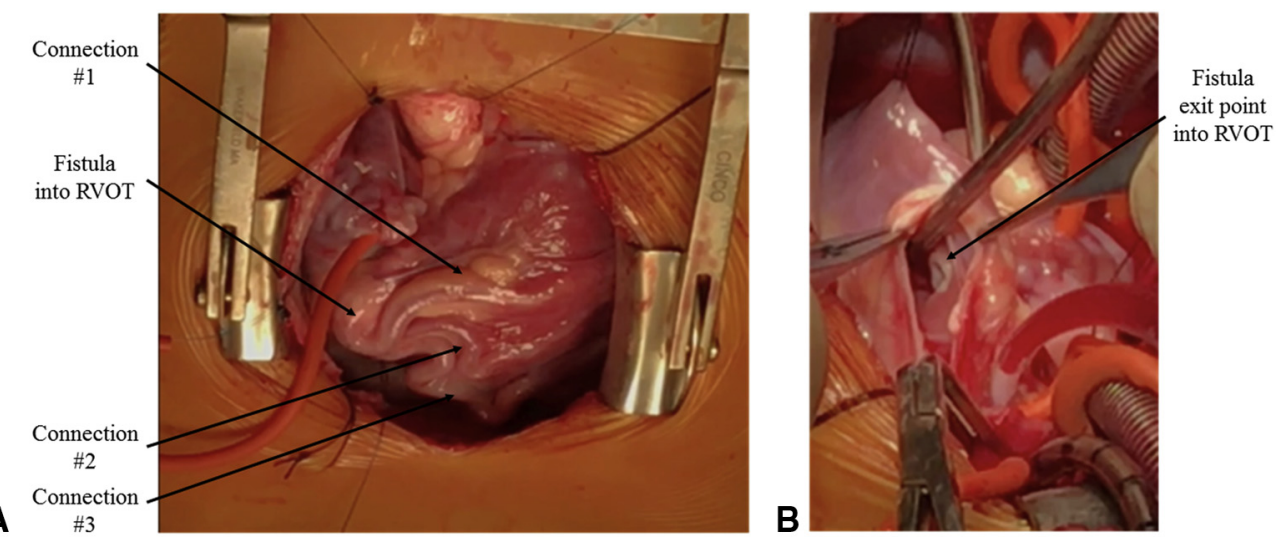

FIGURE 4. Intraoperative picture of the 3 intercoronary connections coalescing into a fistula that enters the RVOT (A) and the exit point of the fistula into the RVOT, observed via a pulmonary arteriotomy (B). RVOT, Right ventricular outflow tract.

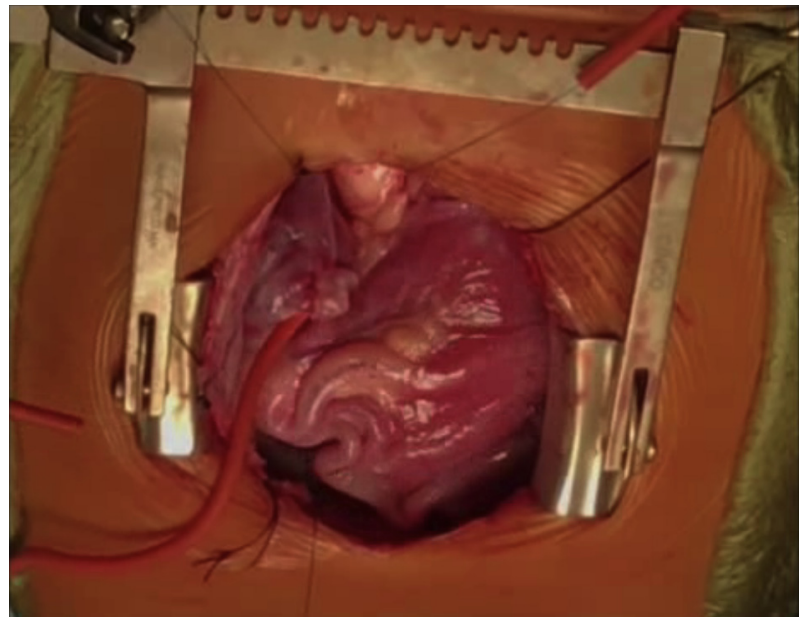

VIDEO 4. Intraoperative video of the 3 intercoronary connections coalescing into a fistula and entering the right ventricular outflow tract. Video available at: http://www.jtcvsonline.org/article/S0022-5223(18) 30395-7/fulltext.

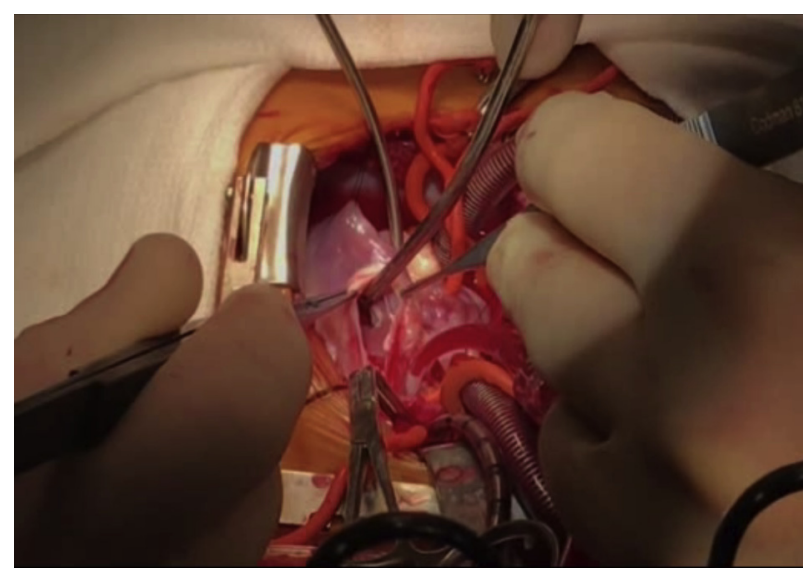

VIDEO 5. Intraoperative video of the exit point of the fistula into the right ventricular outflow tract, observed via a pulmonary arteriotomy during an injection of cardioplegia solution into the aortic root. Video available at: http://www.jtcvsonline.org/article/S0022-5223(18)30395-7/fulltext. 